\title{
Honorary Title
}

National Cancer Institute

\section{Source}

National Cancer Institute. Honorary Title. NCI Thesaurus. Code C92691.

A title conferred on a person, usually in recog nition of their merits, actions or contributions. 